\title{
NMR Studies on Turn Mimetic Analogs Derived from Melanocyte-stimulating Hormones
}

\author{
Min-Kyu Cho", Sung-Soo Kim", Myung-ryul Lee ${ }^{\dagger}$ Joon Shin̈, Jiyong Lee \\ Sung-Kil Lim, Ja-Hyun Baik**, Chang-Ju Yoon", Injae Shin ${ }^{\dagger}$ and Weontae Lee ${ }^{\#, *}$ \\ "Department of Biochemistry and Protein Network Research Center, College of Science, Yonsei University, Seoul 120-749, Korea \\ 'Department of Chemistry, College of Science, Yonsei University, Seoul 120-749, Korea \\ ${ }^{\dagger}$ Department of Internal Medicine, College of Medicine, Yonsei University, Seoul 120-749, Korea \\ **Clinical Research Center, College of Medicine, Yonsei University, Seoul 120-749, Korea \\ "Department of Chemistry, College of Science, Catholic University, Seoul 110-758, Korea
}

Received 21 May 2003, Accepted 4 June 2003

Oligomers with $\alpha$-aminooxy acids are reported to form very stable turn and helix structures, and they are supposed to be useful peptidomimetics for drug design. A recent report suggested that homochiral oxa-peptides form a strong eight-member-ring structure by a hydrogen bond between adjacent aminooxy-acid residues in a $\mathrm{CDCl}_{3}$ solution. In order to design an $\alpha$-MSH analog with a stable turn conformation, we synthesized four tetramers and one pentamer, based on $\alpha$-MSH sequence, and determined the solution structures of the molecules by two-dimensional NMR spectroscopy and simulated annealing calculations. The solution conformations of the three peptidomimetic molecules (TLV, TDV, and TLL) in DMSO-d ${ }_{6}$ contain a stable 7-membered-ring structure that is similar to a $\gamma$ turn in normal peptides. Newly-designed tetramer TDF and pentamer PDF have a ball-type rigid structure that is induced by strong hydrogen bonds between adjacent amide protons and carbonyl oxygens. In conclusion, the aminooxy acids, easily prepared from natural or unnatural amino acids, can be employed to prepare peptidomimetic analogues with well-defined turn structures for pharmaceutical interest.

Keywords: $\alpha$-Aminooxy acids, Peptidomimetics, $\gamma$-MSH, NMR, Turn conformation

\section{Introduction}

Biologically active peptidomimetics with non-amide backbone or unnatural side chains have been widely developed for application as agonists, antagonists, and enzyme inhibitors for important pharmaceutical proteins (Gante, 1994). The short peptide-like molecules that possess one or more non-amide linkage have exhibited good biological activity (Huff, 1991). For example, the scissile peptide bonds that are cleaved by proteases have been replaced by a variety of hydrolytically-stable isosteric moieties, such as hydroxyethylamine (Datta and Veeresa, 2000), ketomethylene (Déziel et al., 1996), silanediol (Sieburth et al., 1998), and phosphinic group (Huixiong et al., 1998) to develop the novel inhibitors for proteases. On the other hand, structurally well-defined backbone-modified peptides (pseudopeptides), such as peptoids (Armand et al., 1998; Kirshenbaum et al., 1998), vinylogous peptides (Hagihara et al., 1992), oligopyrrolinones (Smith et al., 1999), $\beta$-peptides (Gellman, 1998; Chung et al., 2000)), and flat peptides (Crisma et al., 1999), have been prepared to create novel secondary and tertiary structures.

In general, short peptides have not shown well-defined structures but random conformation. Recently, according to the structural (Yang et al., 1996; Yang et al., 1999, Baek et al., 2003) and theoretical studies (Wu et al., 1999) of peptides that are formed by $\alpha$-aminooxy acids, $\alpha$-aminooxy peptides, even short ones, were found to form a novel secondary structure; 8 membered, hydrogen-bonded turn (N-O turns) between carbonyl oxygen and adjacent oxamide $\mathrm{NH}$, irrespective of the side chains. In order to demonstrate that short peptide $\alpha$ melanocyte-stimulating hormone ( $\alpha$-MSH) analogs containing $\alpha$-aminooxy acids have well-defined conformation and potentially useful biological properties, we synthesized
*To whom correspondence should be addressed.

Tel: 82-2-2123-2706; Fax: 82-2-363-2706

E-mail: wlee@ spin.yonsei.ac.kr 
peptidomimetics containing $\alpha$-aminooxy moiety and determined their solution structures by NMR. The target peptidomimetics were selected to mimic the stable turn secondary structure of $\alpha$-MSH. We previously showed that the rigid turn conformation of $\alpha-\mathrm{MSH}$, as well as the side chain polarization, is crucial for binding to its receptor(s) and important for its biological activity. Therefore, newlydesigned peptidomimetic analogs can be used as a template for designing novel anti-obesity drugs.

\section{Materials and Methods}

Sample preparations Tetramers containing L- or D-valine and L-leucine aminooxy acid (TLV, TDV, and TLL, respectively) were chosen as peptidomimetics for structural studies and synthesized by sequential coupling reactions (Fig. 1). In addition, another tetramer and pentamer containing D-phenylalanine aminooxy acid (TDF and PDF) were also synthesized. All of these 5 analogs were synthesized by Prof. Injae Shin's laboratory at the Department of Chemistry in Yonsei University. Aminooxy acid 1 ((L or D)-PhthN$\mathrm{O}-\mathrm{Val}-\mathrm{OH}$ and (D)-PhthN-O-Leu-OH) that was incorporated into tetramers were prepared according to the procedure that we developed (Shin et al., 2000). The prepared aminooxy acid 1 was coupled to Trp methyl ester using N-hydroxybenzotriazole (HOBt, 1.1 equiv.), 2-(1H-benzotriazole-1-yl)-1,1,3,3-tetramethyluronium hexafluorophosphate (HBTU, 1.1 equiv.), and diisopropyl ethyl amine (DIEA, 1.1 equiv.) as coupling reagents to give the corresponding dimer $\mathbf{2}$. The removal of a phthaloyl group in $\mathbf{2}$ by hydrazine monohydrate, followed by coupling to Boc-D-Phe-OH using the same coupling reagents, yielded trimer 3 . The deprotection of a Boc group in 3 by TFA : thioanisole : $\mathrm{CH}_{2} \mathrm{Cl}_{2}(6$ : $1: 13$ ), and the subsequent coupling to $\mathrm{Ac}-\mathrm{Asp}(\mathrm{Bn})-\mathrm{OH}$ and debenzylation of a benzyl ester, produced tetramer 4 .

NMR spectroscopy For the NMR experiments, all of the samples were dissolved in DMSO- $\mathrm{d}_{6}$ (Cambridge Isotope Inc.) at a concentration of $2 \mathrm{mM}$. The NMR measurements were performed at $25^{\circ} \mathrm{C}$ with a $500 \mathrm{MHz}$ Bruker DRX500 spectrometer that was equipped with a SGI workstation as described our previous research (Koo et al., 2002). Data were collected with a $7002 \mathrm{~Hz}$ spectral width, 2048 complex points in $\mathrm{t}_{2}$ and 128 increments in $\mathrm{t}_{1}$ for ${ }^{1} \mathrm{H}-{ }^{1} \mathrm{H}$ two-dimensional total correlation spectroscopy (TOCSY) with a mixing time of $69 \mathrm{~ms}$ (Davis and Bax, 1985) and for 1H-1H twodimensional rotating frame nuclear Overhauser enhancement spectroscopy (ROESY) experiments (Bax. and Davis, 1985). The 2D ROESY with mixing times of $100-300 \mathrm{~ms}$ was served to perform the backbone sequential assignments and to obtain the distance constraints. 2-D NOESY spectra of PDF were recorded with mixing times of $600 \mathrm{~ms}$. Constraints for the dihedral angles were deduced on the basis of the ${ }^{3} J_{\mathrm{HN} \alpha}$ coupling constants from the proton 1D spectrum. All of the data were transferred to an SGI Indigo $^{2}$ workstation and processed by a XWIN-NMR package (Bruker Instruments, Rheinstetten, Germany).

Structure calculations Solution structures were calculated using

(A)

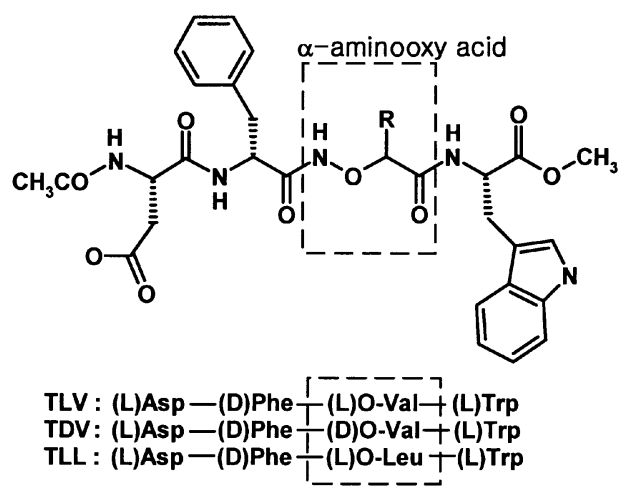

(B)
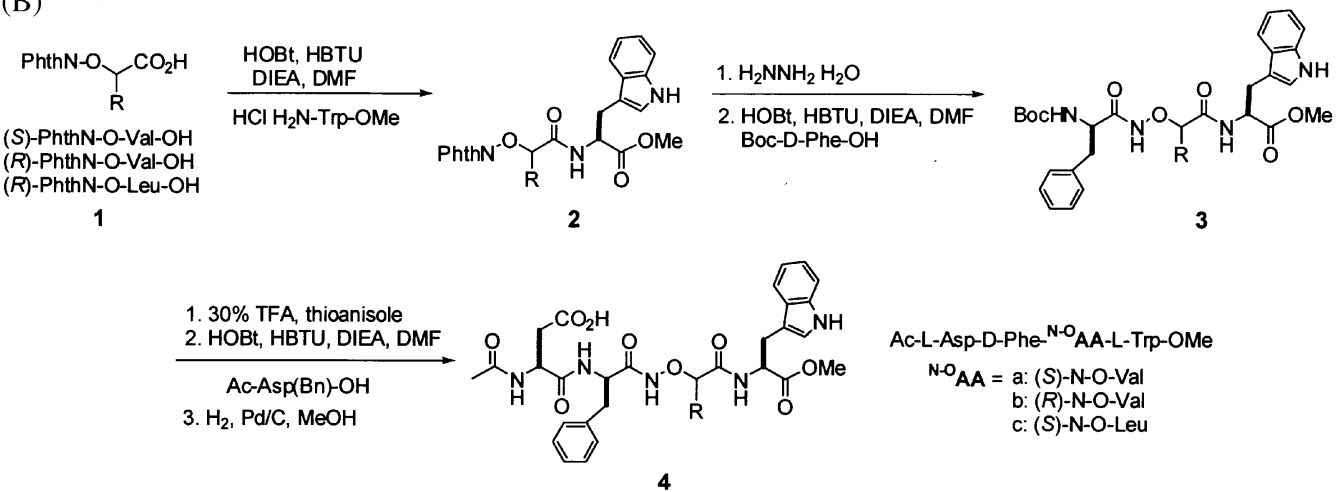

Fig. 1. Chemical structures of $\alpha-M S H$ analogs, TLV, TDV, and TLL. The residues in the dotted line are $\alpha$-aminooxy acids. R represents the aliphatic chains of valine or leucine. (B) Synthetic schemes of the tetramers. 


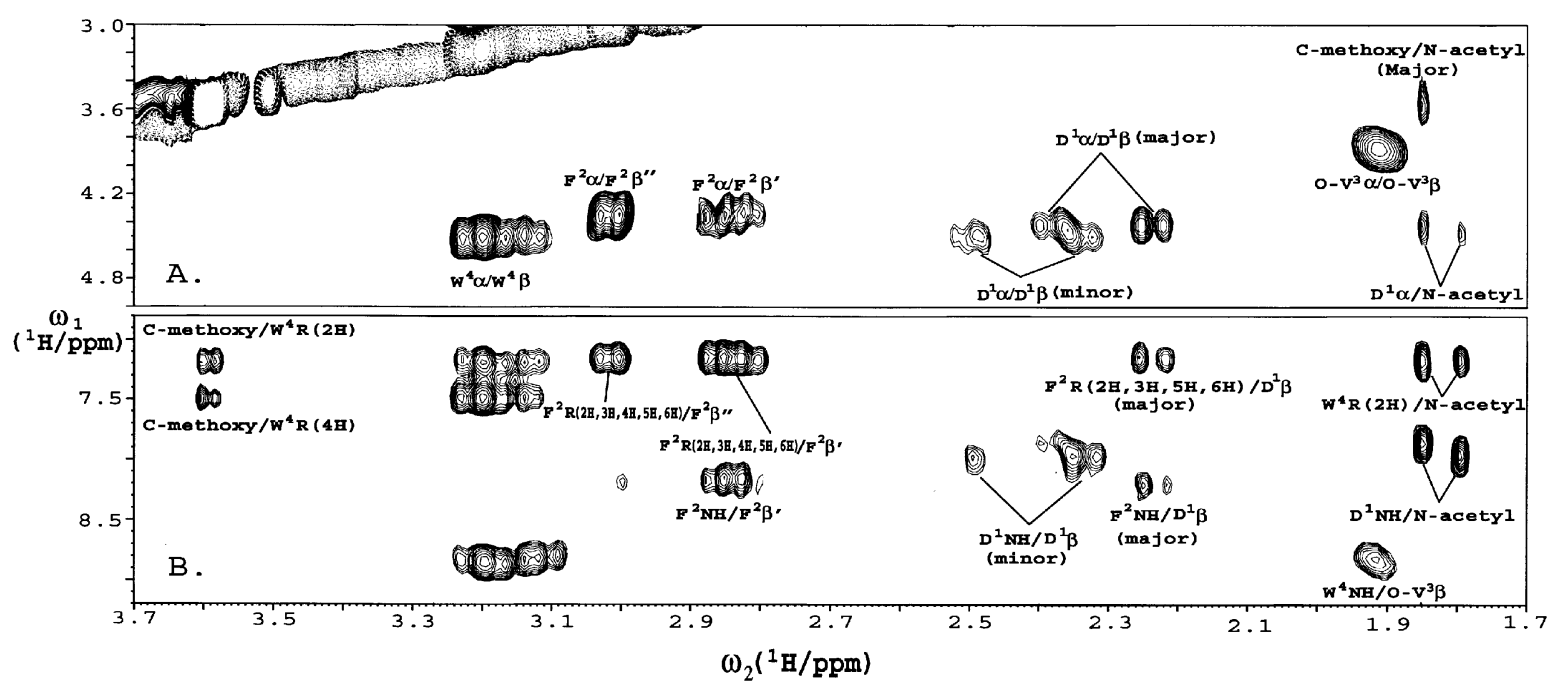

Fig. 2. 2D ROESY spectra of TLV. The amide region (A) and aliphatic region (B) of ROESY spectra show the different NOE patterns of the major and minor structures of TLV. The major structure has a NOE between an acetyl group in N-terminal and a methoxy group in the C-terminal, suggesting the presence of an additional hydrogen bond between $\mathrm{Asp}^{1}$ and $\operatorname{Trp}^{4}$.

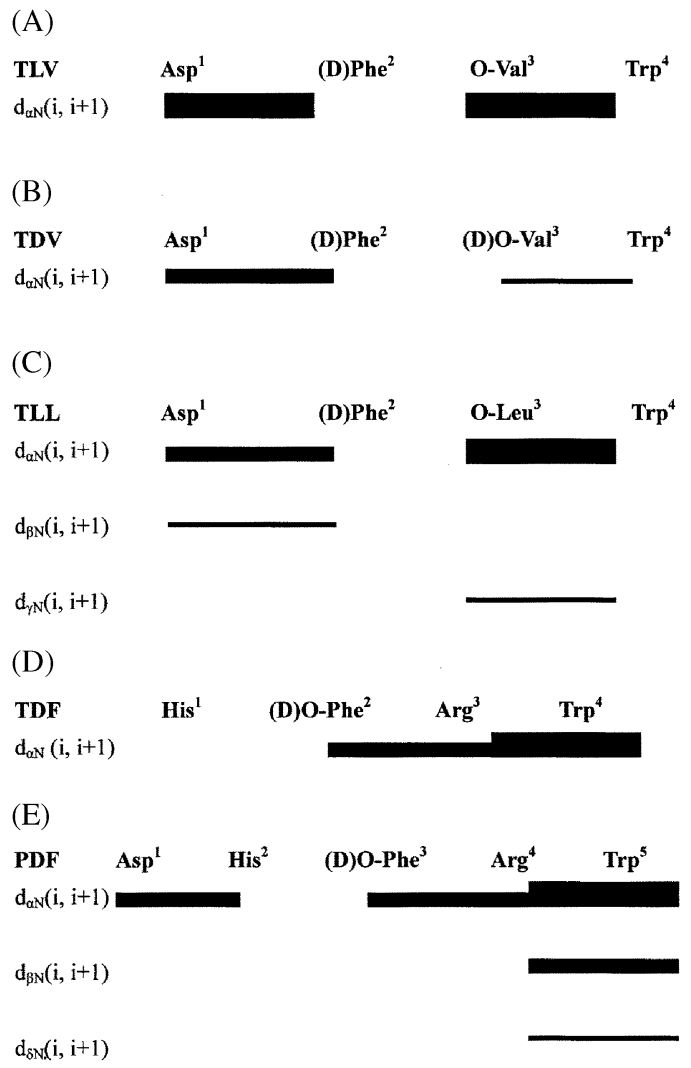

Fig. 3. The sequential and short-range ROEs of (A) TLV, (B) TDV, (C) TLL, (D) TDF, and NOEs of (E) PDF. The mixing times are 100-300 ms and $600 \mathrm{~ms}$ for ROEs and NOEs, respectively. The intensities are represented by the thickness of the lines. (F) A methanol titration data showing chemical shift changes of amide protons of TDV with increasing amounts of methanol at $25^{\circ} \mathrm{C}$.

the simulated annealing method, beginning with an extended structure that was generated by the CNS Program (version 1.0) (Brüger et al., 1998). The distance restraints from the ROESY and NOESY spectra were assigned as strong, medium, or weak. All of

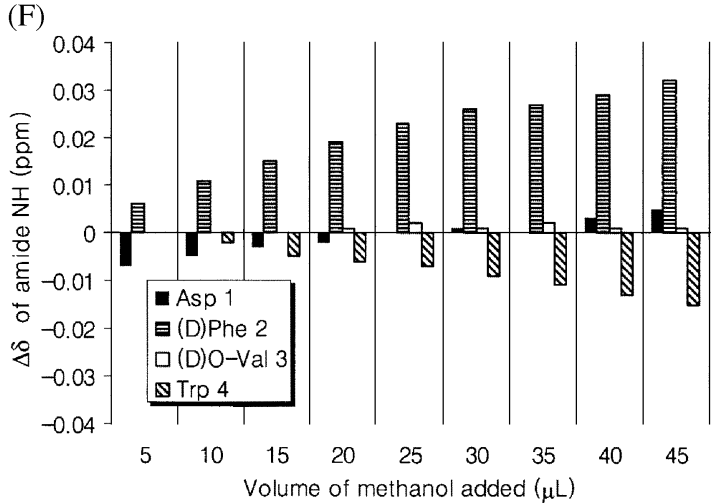

the categories had a lower limit of $1.8 \AA$, with upper limits of 2.7 , 3.3, and $5.0 \AA$ for the strong, medium, or weak intensities, respectively. The initial structures were generated using distance geometry and then used during the simulated annealing protocol 
Table 1. ${ }^{1} \mathrm{H}-\mathrm{NMR}$ chemical shifts

\begin{tabular}{|c|c|c|c|c|c|}
\hline \multirow{2}{*}{ Molecule } & \multirow{2}{*}{ Residue } & \multicolumn{4}{|r|}{ Chemical shift (ppm) } \\
\hline & & $\mathrm{NH}$ & $\alpha \mathrm{H}$ & $\beta \mathrm{H}$ & Others \\
\hline \multirow[t]{4}{*}{ TLV } & (L)Asp & 7.90 & 4.43 & $2.38,2.23$ & \\
\hline & (D)Phe & 8.20 & 4.38 & $3.01,2.84$ & $2 \mathrm{H}, 6 \mathrm{H}(7.19) 4 \mathrm{H}(7.21) 3 \mathrm{H}, 5 \mathrm{H}(7.27)$ \\
\hline & (L)O-Val & 11.67 & 3.92 & 1.92 & $\gamma \mathrm{CH}_{3}(0.86,0.67)$ \\
\hline & $(\mathrm{L}) \operatorname{Trp}$ & 8.89 & 4.52 & 3.20 & $2 \mathrm{H}(7.27) 4 \mathrm{H}(7.53) 5 \mathrm{H}(6.98) 6 \mathrm{H}(7.05) 7 \mathrm{H}(7.33) \mathrm{NH}(10.87)$ \\
\hline \multirow[t]{4}{*}{ TDV } & (L)Asp & 7.89 & 4.35 & $2.34,2.21$ & \\
\hline & (D)Phe & 8.23 & 4.35 & $3.05,2.80$ & $2 \mathrm{H}, 6 \mathrm{H}(7.19) 4 \mathrm{H}(7.21) 3 \mathrm{H}, 5 \mathrm{H}(7.29)$ \\
\hline & (D)O-Val & 11.59 & 4.08 & 2.03 & $\gamma \mathrm{CH}_{3}(0.94,0.83)$ \\
\hline & $(\mathrm{L}) \operatorname{Trp}$ & 8.77 & 4.55 & 3.15 & $2 \mathrm{H}(7.25) 4 \mathrm{H}(7.48) 5 \mathrm{H}(6.96) 6 \mathrm{H}(7.04) 7 \mathrm{H}(7.32) \mathrm{NH}(10.94)$ \\
\hline \multirow[t]{4}{*}{ TLL } & (L)Asp & 8.10 & 4.53 & $2.34,2.26$ & \\
\hline & (D)Phe & 8.31 & 4.41 & $2.97,2.83$ & $2 \mathrm{H}, 6 \mathrm{H}(7.19) 4 \mathrm{H}(7.21) 3 \mathrm{H}, 5 \mathrm{H}(7.24)$ \\
\hline & (L)O-Leu & 11.61 & 4.13 & 1.33 & $\gamma \mathrm{CH}(1.69) \delta \mathrm{CH}_{3}(0.83)$ \\
\hline & (L)Trp & 8.76 & 4.49 & $3.21,3.09$ & $2 \mathrm{H}(7.17) 4 \mathrm{H}(7.52) 5 \mathrm{H}(6.99) 6 \mathrm{H}(7.06) 7 \mathrm{H}(7.34) \mathrm{NH}(10.80)$ \\
\hline \multirow[t]{4}{*}{ TDF } & (L)His & 8.16 & 4.32 & $2.83,2.74$ & $2 \mathrm{H}(7.42) 4 \mathrm{H}(7.13)$ \\
\hline & (D)O-Phe & 11.87 & 4.39 & $2.81,2.81$ & $2 \mathrm{H}, 6 \mathrm{H}(7.19) 4 \mathrm{H}(7.21) 3 \mathrm{H}, 5 \mathrm{H}(7.23)$ \\
\hline & (L)Arg & 8.21 & 4.18 & $1.52,1.40$ & $\gamma \mathrm{CH}_{2}(1.25,1.25) \delta \mathrm{CH}_{2}(2.99,2.99) \varepsilon \mathrm{NH}(7.43)$ \\
\hline & (L)Trp & 7.98 & 4.47 & $3.08,2.93$ & $2 \mathrm{H}(7.10) 4 \mathrm{H}(7.59) 5 \mathrm{H}(6.93) 6 \mathrm{H}(7.40) 7 \mathrm{H}(7.02) \mathrm{NH}(10.77)$ \\
\hline \multirow[t]{5}{*}{ PDF } & (L)Asp & 8.21 & 4.45 & $2.51,2.42$ & \\
\hline & (L)His & 8.18 & 4.37 & $2.96,2.86$ & $2 \mathrm{H}(7.49) 4 \mathrm{H}(7.09)$ \\
\hline & (D)O-Phe & 11.84 & 4.42 & $2.89,2.89$ & $2 \mathrm{H}, 6 \mathrm{H}(7.05) 4 \mathrm{H}(7.07) 3 \mathrm{H}, 5 \mathrm{H}(7.12)$ \\
\hline & (L)Arg & 8.21 & 4.21 & $1.56,1.42$ & $\gamma \mathrm{CH}_{2}(1.27,1.27) \delta \mathrm{CH}_{2}(2.99,2.99) \varepsilon \mathrm{NH}(7.41)$ \\
\hline & (L)Trp & 7.58 & 4.49 & $3.09,3.95$ & $2 \mathrm{H}(7.12) 4 \mathrm{H}(7.59) 5 \mathrm{H}(6.96) 6 \mathrm{H}(7.28) 7 \mathrm{H}(7.02) \mathrm{NH}(10.71)$ \\
\hline
\end{tabular}

(Clore et al., 1986). Solution structures of the tetramers were analyzed from 39 out of $50\langle\mathrm{SA}\rangle_{\mathrm{k}}$ structures for TLV, 36 out of 50 $\langle\mathrm{SA}\rangle_{\mathrm{k}}$ structures for TDV, 35 out of $50\langle\mathrm{SA}\rangle_{\mathrm{k}}$ structures for TLL, 38 out of $50\langle\mathrm{SA}\rangle_{\mathrm{k}}$ structures for TDF, and 39 out of $50\langle\mathrm{SA}\rangle_{\mathrm{k}}$ structures for PDF, which had the lowest overall energies and no constraint violations. All of the structures were displayed and further analyzed using the Insight II Program (version 98.0).

\section{Results and Discussion}

Resonance assignments of peptide analogs containing $L$ or D-aminooxy acids Figure 2 shows the amide and aliphatic region of the ROESY spectrum of TLV. Since peptides were synthesized with acetylation at the N-terminal and esterification at the $\mathrm{C}$-terminal, the first and last residues have ROEs with the $\mathrm{N}$-terminal acetyl and C-terminal methoxy groups, respectively. Sequential resonance assignments (Wüthrich, 1986) were performed from the combined use of the TOCSY and ROESY spectra. Since each tetramer has two molecular conformations in a solution, two sets of sequential resonance connectivity were observed.

The side chain proton resonances were easily identified by TOCSY connectivity. Most of the ROE intensities were measured at mixing times of 150-300 ms. From the ROE growth-curve (data not shown), it was ascertained that the spin-diffusion effects for these molecules are not significant at mixing times of 150-300 ms for the ROESY experiments. Interestingly, the correlation from the amide proton of the aminooxy acid is missing, possibly because the magnetization transfer from the NH was blocked for some reason. Table 1 lists the complete chemical shift assignments of the molecules.

Stereo-specific assignment and identification of hydrogen bonds It is possible to identify the rotameric state for a given side chain, and hence the stereospecific assignment of its $\beta$-protons. Figure 2 shows how the stereospecific assignments of the $\beta$-methylene protons in TLV can be made on the basis of the intraresidue ROEs $d_{\alpha \beta}, d_{\alpha \beta}, d_{N \beta}$, and $d_{N \beta}$ ". For identifying the slowly-exchanging amide hydrogen atoms, the temperature dependence of the $\mathrm{NH}$ chemical shifts was also measured as a function of temperature. The amide proton of the aminooxy acid in each compound exhibited a very small temperature dependence, indicating the presence of a hydrogen bond that is caused by this proton. In addition, the fact that the $\mathrm{NH}$ proton of the $\mathrm{Asp}^{1}$ has a relatively small temperature coefficient could be evidence of another hydrogen bond that is induced by the $\mathrm{NH}$ of $\mathrm{Asp}^{1}$.

To characterize the protected hydrogen atoms, a methanol titration experiment was performed for the aminooxy acid analog. When methanol was added to the DMSO- $\mathrm{d}_{6}$ solution of tetramer, amide protons of $\mathrm{Phe}^{2}$ and $\operatorname{Trp}^{4}$ were quickly shifted to downfield, whereas those of $\mathrm{Asp}^{1}$ and O-Val ${ }^{3}$ 
(A)

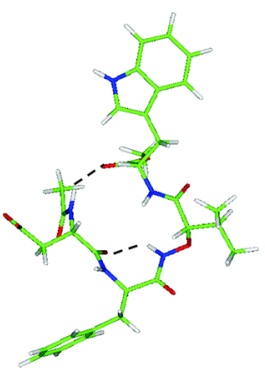

TLV

(C)

Major

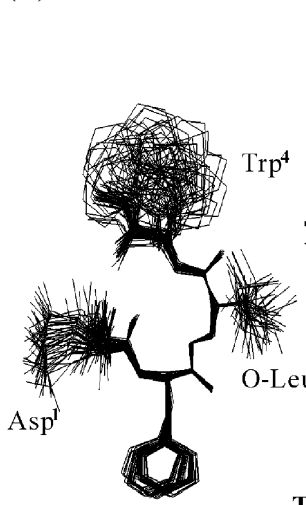

(D)Phe
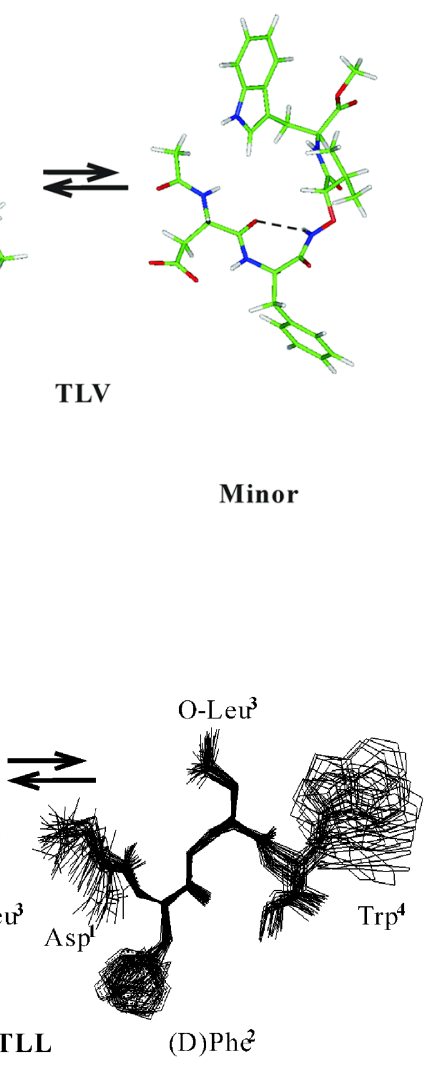

(B)

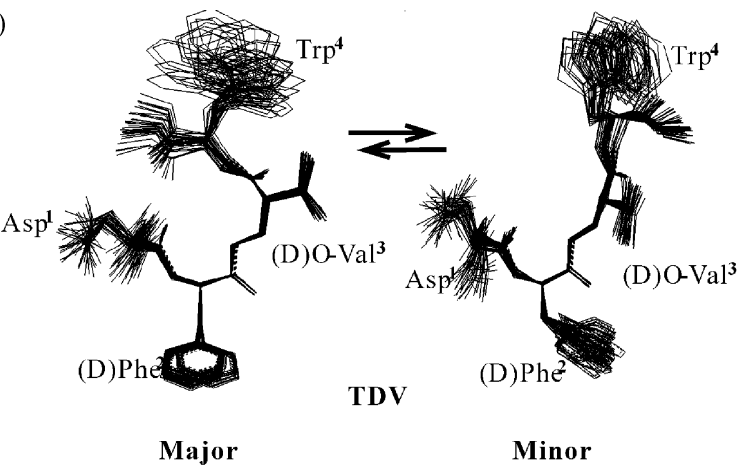

(D)

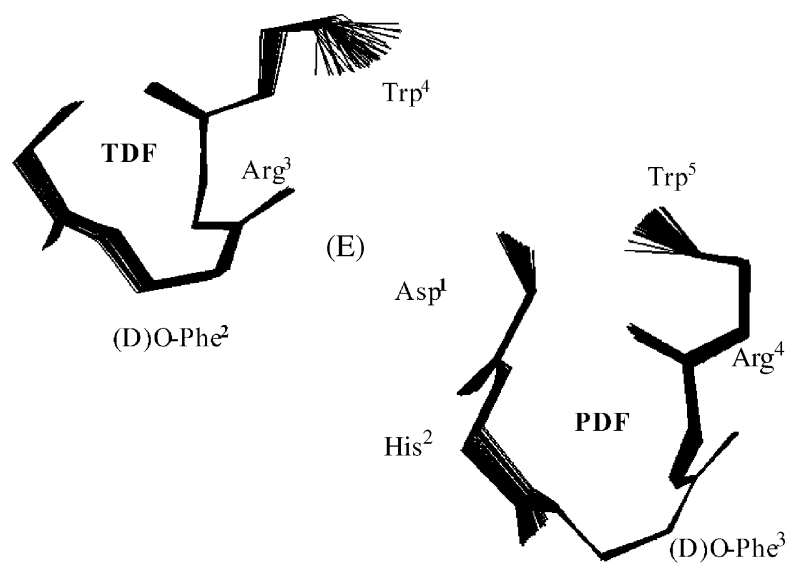

Fig. 4. The energy-minimized average structure of TLV in stick model (A) and superposition of the final simulated-annealing $\left.(<\mathrm{SA}\rangle_{\mathrm{k}}\right)$ structures of (B) TLL, (C) TDV, (D) TDF, and (E) PDF, respectively. Hydrogen bond positions were represented by dotted lines.

changed less than $0.01 \mathrm{ppm}$ (Fig. 3). This data strongly suggest that the amide protons of $\mathrm{Phe}^{2}$ and $\mathrm{Trp}^{4}$ are solvent exposed, whereas those of $\mathrm{Asp}^{1}$ and $\mathrm{O}-\mathrm{Val}^{3}$ are primarily protected from the solvent. However, it is interesting to see that the $\mathrm{NH}$ of $\mathrm{Asp}^{1}$ showed a larger chemical shift change than the $\mathrm{NH}$ of $\mathrm{O}-\mathrm{Val}^{3}$, suggesting that the hydrogen bond that is caused by the $\mathrm{NH}$ of $\mathrm{Asp}^{1}$ is thermodynamically unstable. Based on the NMR data and modeling calculations, we observed that the two structures for each molecule were at a conformational equilibrium in the DMSO-d $\mathrm{d}_{6}$ solution (Fig. 4). The major conformation of the molecule has two hydrogen bonds, whereas that of the minor form shows one hydrogen bond. In the ROESY spectrum (Fig. 2), the N-terminal acetyl protons of the major conformation showed a ROE cross peak with the C-terminal methoxy protons, supporting the presence of the hydrogen bond between $\mathrm{Asp}^{1}$ and $\operatorname{Trp}^{4}$.

Solution structures of peptide analogs containing $\mathbf{L}$ or $\mathbf{D}$ aminooxy acids Yang et al. (1999) showed that $\alpha$ aminooxy acid induced a strong 8-membered-ring with a hydrogen bond (N-O turn) between the adjacent aminooxyacid residues containing a diversity of side chains. However, there were two possibilities for our molecules to form hydrogen bonds between the adjacent residues. The $\alpha$ aminooxy acid in TLV, TDV, and TLL caused a 7-membered ring structure between the carbonyl oxygen of $\mathrm{Asp}^{1}$ and the $\mathrm{NH}$ of $\mathrm{O}-\mathrm{Val}^{3}$. This hydrogen-bonding pattern was analogous to a $\gamma$-turn that is found in normal peptides, except for an extra oxygen atom in the backbone. Simultaneously, other molecules at the conformational equilibrium had additional hydrogen bonds between the $\mathrm{NH}$ of $\mathrm{Asp}^{1}$ and the carbonyl oxygen of $\mathrm{Trp}^{4}$, which enabled them to form a huge 15membered ring. There was a good hydrogen bond in the 7membered ring, as indicated by the $\mathrm{O} \cdots \mathrm{H}$ distance of 2.30 $\AA$ and the $\mathrm{O} \cdots \mathrm{HN}$ angle of $142^{\circ}$, on average. The ball-like conformation of TDF and PDF was calculated based on the distance constraints that were obtained from ROESY and NOESY, as well as the information about the hydrogen bonds that were obtained from the titration experiment. TDF had a 12-membered ring, whereas PDF has an 18-membered ring structure.

In contrast to the peptides of aminooxy acids in $\mathrm{CDCl}_{3}$ (Yang et al., 1999), our molecules in DMSO-d $\mathrm{d}_{6}$ strongly prefers a 7-membered hydrogen-bonded local structure. This is probably due to the solvent effect on the conformational stability. This result is not surprising because Peter et al. (Peter, 2000) reported data of molecular dynamics simulations for the conformational behavior of peptide analogs that were formed by $\alpha$-aminooxy acids. He confirmed the importance of treating solvent degrees of freedom explicitly in calculating 
structures. They found that the conformations of the peptide analogs in water differ from the conformations in chloroform. In conclusion, the aminooxy acids, easily prepared from natural or unnatural amino acids, can be employed to prepare pseudopetides with well-defined secondary structures. We believe that these peptidomimetics may be useful for the development of novel drug candidates.

Acknowledgments This work was supported by the 2001 Good Health R\&D Project, Ministry of Health, and Welfare (01-PJ1-PG3-21500-0041), the NRL Program of MOST NRDP (M1-0203-00-0020) (W. Lee), and the Center for Integrated Molecular Systems (KOSEF, I. Shin).

\section{References}

Armand, P., Kirshenbaum, K., Goldsmith, R. A., Farr-Jones, S., Barron, A. E., Truong, K. T., Dill, K. A., Mierke, D. F., Cohen, F. E., Zuckermann, R. N. and Bradley, E. K. (1998) NMR determination of the major solution conformation of a peptoid pentamer with chiral side-chains. Proc. Natl. Acad. Sci. USA 95, 4309-4314.

Baek, B.-H., Lee, M.-R., Kim, K.-Y., Cho, U.-I., Boo, D. W. and Shin, I. (2003) Novel consecutive beta- and gamma-turn mimetics composed of alpha-aminooxy tripeptides Org. Lett. 5, 971-974.

Bax, A. and Davis, D. G. (1985) MLEV-17 based 2D homonuclear magnetization transfer spectroscopy. J. Magn. Reson. 65, 355-360.

Brüger, A. T., Adams, P. D., Clore, G. M., DeLano, W. L., Gros, P., Gross-Kunstleve, R. W., Jing, J.-S., Kuszewski, J., Nilges, M., Pannu, N. S., Read, R. J., Rice, L. M., Simonson, T. and Warren, G. (1998) Crystallography and NMR system-a new software suite for macromolecular structure determination. Acta Cryst. D54, 905-921.

Chung Y. J., Huck, B. R., Christianson, L. A., Stanger, H. E., Krauthauser, S., Powell, D. R. and Gellman, S. H. (2000) Stereochemical control of hairpin formation in beta-peptides containing dinipecotic acid reverse turn segments. J. Am. Chem. Soc. 122, 3995-4004.

Clore, G. M., Brunger, A. T., Karplus, M. and Gronenborn, A. M. (1986) Application of molecular dynamics with interproton distance restraints to three-dimensional protein structure determination. A model study of crambin. J. Mol. Biol. 191, 523-551.

Crisma, M., Formaggio, F., Toniolo, C., Yoshikawa, T. and Wakamiya, T. (1999) Flat peptides. J. Am. Chem. Soc. 121, 3272-3278.

Datta, A. and Veeresa, G. (2000) A stereoselective route to hydroxyethylamine dipeptide isosteres. J. Org. Chem. 65, 76097611.

Davis, D. G. and Bax, A. (1985) Assignment of complex 1H NMR spectra via two-dimensional homonuclear HartmannHahn spectroscopy. J. Am. Chem. Soc. 107, 2820-2821.

Déziel, R., Plante, R., Caron, V., Grenier, L., Llinas-Brunet, M., Duceppe, J.-S., Malenfant, E. and Moss, N. (1996) Practical and diastereoselective synthesis of ketomethylene dipeptide isosteres of the type AA-psi(Coch2)Asp. J. Org. Chem. 61,
2901-2903.

Gante, J. (1994) Peptidomimetics-tailored enzyme inhibitors. Angew. Chem. Int. Ed. Engl. 33, 1699-1720.

Gellman, S. H. (1998) Foldamers-A manifesto. Acc. Chem. Res. 31, 173-180.

Hagihara, M., Anthony, N. J., Stout, T. J., Clardy, J. and Schreiber, S. L. (1992) Vinylogous polypeptides-an alternative peptide backbone. J. Am. Chem. Soc. 114, 6568-6570.

Huff, J. R. (1991) HIV Protease: A novel chemotherapeutic target for AIDS. J. Med. Chem. 34, 2305-2314.

Huixiong, C., Noble, F., Coric, P., Fournie-Zaluski, M. and Roques, B. P. (1998) Aminophosphinic Inhibitors as Transitionstate analogs of enkephalin-degrading enzymes-a class of central analgesics. Proc. Natl. Acad. Sci. USA 96, 1202812033.

Kirshenbaum, K., Barron, A. E., Goldsmith, R. A., Armand, P., Bradley, E. K., Truong, K. T., Dill, K. A., Cohen, F. E. and Zuckermann, R. N. (1998) Sequence-Specific Polypeptoids - A Diverse Family of Heteropolymers with Stable Secondary Structure. Proc. Natl. Acad. Sci. USA 95, 4303-4308.

Koo, B. -K., Kim, M. -H., Lee, S. -T. and Lee, W. (2002) Purification and spectroscopic characterization of the human tyrosine kinase-6 SH3 domain. J. Biochem. Mol. Biol. 35, 343347.

Li, S.-Z., Lee, J.-H., Lee, W., Yoon, C.-J., Baik, J.-H. and Lim, S.K. (1999) Type I $\beta$-turn conformation is important for biological activity of the melanocyte-stimulating hormone analogues. Eur. J. Biochem. 265, 1-12.

Peter, C., Daura, X. and van Gunsteren, W. F. (2000) Peptides of aminoxy acids: A molecular dynamics simulation study of conformational equilibria under various conditions. J. Am. Chem. Soc. 122, 7461-7466.

Shin, I., Lee, M-r., Lee, J., Jung, M., Lee, W. and Yoon, J. (2000) Synthesis of optically-active phthaloyl D-aminooxy acids from L-amino-acids or L-hydroxy acids as building-blocks for the preparation of aminooxy peptides. J. Org. Chem. 65, 76677675.

Sieburth, S. M., Nittoli, T., Mutahi, A. M. and Guo, L. (1998) Silanediols-A new class of potent protease inhibitor. Angew. Chem. Int. Ed. 37, 812-814.

Smith, A. B. III., Benowitz, A. B., Sprengeler, P. A., Barbosa, J., Guzman, M. C., Hirshmann, R., Schweiger, E. J., Bolin, D. R., Nagy, Z., Campbell, R. M., Cox, D. C. and Olson, G. L. (1999) Design and synthesis of a competent pyrrolinonepeptide hybrid ligand for the class-II major histocompatibility complex protein HLA-DR1. J. Am. Chem. Soc. 121, 92869298.

Yang, D., Ng, F.-F., Li, Z.-J., Wu, Y.-D., Chan, K. W. K. and Wang, D. -P. (1996) An unusual turn structure in peptides containing alpha-aminoxy acids. J. Am. Chem. Soc. 118, 97949795.

Yang, D., Qu, J., Ng, F.-F., Wang, X.-C., Cheung, K.-K., Wang, D.-P. and Wu, Y.-D. (1999) Novel turns and helices in peptides of chiral alpha-aminoxy acids. J. Am Chem. Soc. 121, 589-590.

Wu, Y.-D., Wang, D.-P., Chan, K. W. K. and Yang, D. (1999) Theoretical-study of peptides formed by aminoxy acids. J. Am. Chem. Soc. 121, 11189-11196.

Wuthrich, K. (1986) NMR of proteins and nucleic acids, Wiley, New York, USA. 